\title{
Did the Revision of the Japanese Medical Payment System Work Properly?- An Analysis of Averages and Variances of Length of Hospital Stay for Type 2 Diabetes Patients by Individual Hospital
}

\author{
Kazumitsu Nawata1, Koichi Kawabuchi ${ }^{2}$ \\ ${ }^{1}$ Graduate School of Engineering, University of Tokyo, Tokyo, Japan \\ ${ }^{2}$ Graduate School of Medical and Dental Sciences, Tokyo Medical and Dental University, Tokyo, Japan \\ Email: nawata@tmi.t.u-tokyo.ac.jp, kawabuchi.hce@tmd.ac.jp
}

Received 11 February 2016; accepted 8 April 2016; published 11 April 2016

Copyright @ 2016 by authors and Scientific Research Publishing Inc.

This work is licensed under the Creative Commons Attribution International License (CC BY).

http://creativecommons.org/licenses/by/4.0/

\section{(c) (i) Open Access}

\begin{abstract}
We evaluated the effects of the 2010 revision of the medical payment system on the length of stay (LOS). In this analysis, we assessed not only the average length of stay (ALOS), but also variance of LOS at individual hospitals. We used a dataset of 18,641 type 2 diabetes patients collected from 51 general hospitals. The variables found to affect LOS were age, comorbidities, complications, acute hospitalization, introduced by other hospitals, winter, one-week hospitalization, specific hospitalization period, and principal diseases coded E11.5, E11.6 and E11.7. Although the effect was marginal, the 2010 revision did reduce ALOS, and the reduction was larger as ALOS became longer. On the other hand, we did not find that the variance of LOS within hospitals became smaller. The results of the study suggest that new incentives and assistance to hospitals to help them make efficient use of medical information are needed.
\end{abstract}

Keywords

Type 2 Diabetes, Length of Hospital Stay, Analysis of Variances

\section{Introduction}

In June 2015, the advisory committee of the Ministry of Health, Labour and Welfare [1] submitted the very im-

How to cite this paper: Nawata, K. and Kawabuchi, K. (2016) Did the Revision of the Japanese Medical Payment System Work Properly? -An Analysis of Averages and Variances of Length of Hospital Stay for Type 2 Diabetes Patients by Individual Hospital. Health, 8, 505-517. http://dx.doi.org/10.4236/health.2016.86054 
portant report, "Japan Vision: Healthcare 2035", to Minister Shiozaki. The discussion on "sustainable financing" of the Japanese medical system is one of the most important parts of this report [2]. Japanese medical costs reached 40 trillion yen in fiscal year 2013 [3]. And they are expected to increase rapidly as the population ages. Japan has a mandatory health insurance system. Direct payments by patients represented just $12 \%$ of total costs, while public expenditures and insurance premiums constituted $39 \%$ and $49 \%$ of these costs, respectively. Therefore, it is truly a serious problem whether the Japanese medical payment system is financially sustainable or not.

A medical payment system based on the Diagnosis Procedure Combination (DPC) was introduced in April 2003 for special functioning hospitals; these included university hospitals and leading national medical institutes considered to have the ability to demonstrate the best medical practices in Japan. Hence, these hospitals have been heavily supported by the government. The system has been called the DPC/PDPS (per diem payment system) since 2010. Unlike the Diagnosis-Related Group/Prospective Payment System (DRG/PPS) used in several other countries, the Japanese DPC/PDPS is a per diem prospective payment system. It identifies three periods (Periods I and II and the Specific Hospitalization Period), and daily payments in the periods are determined for each DPC code. For details, see Nawata et al. [4]. The DPC/PDPS was expanded to general hospitals in April 2004, and it has been revised every other year since then.

Joining the DPC/PDPS is not compulsory; hospitals can choose freely to join or not if they satisfy the necessary conditions [5]. As of April 2013, 1496 hospitals were participating in the DPC/PDPS, and additional 244 hospitals were preparing to join (hereafter, we refer to these hospitals as DPC hospitals). DPC hospitals compromised $23.1 \%$ of the 7528 general hospitals in Japan, and had 509,482 beds, $56.6 \%$ of the 899,385 beds in all general hospitals [6]. Table 1 presents the number of hospitals joined the DPC/PDPS and beds by hospital size. A clear trend is evident in these data; namely, that likelihood of DPC participation increases with hospital size. Among small hospitals with fewer than 100 beds, only $5.7 \%$ have joined the DPC/PDPS. These hospitals had $10.3 \%$ of the beds in this category. Among middle-sized hospitals with 200 - 400 beds, $41.6 \%$ had joined, with $64.8 \%$ of beds in this category. Finally, among large hospitals with 500 or more beds, $65.1 \%$ had joined, representing more than three-quarters $(77.6 \%)$ of the beds in this category. The DPC/PDPS has been revised every other year since 2004. In general, the three periods have been shortened, and daily payments reduced in these revisions. It is absolutely necessary to evaluate the effects of the revisions properly for efficient use of medical resources in Japan.

In this paper, we analyze the length of stay (LOS) in hospitals for diabetes patients. The medical cost of diabetes in Japan was 1208 billion yen in fiscal year 2013, accounting for 3\% of total medical costs. It is thus a very costly disease [3]. This is the case worldwide. Estimates of the International Diabetes Federation (IDF) put the worldwide total medical cost for diabetes at $\$ 612$ billion in 2014 [7]. Diabetes may also cause more serious and costly complications [8] [9]. Various researchers have pointed out that the risk of fatality increases, LOS becomes longer, and medical costs increase if a patient has diabetes as a comorbidity [10]-[16]. As a result, the true medical cost of diabetes might be much higher than the direct one [17]. In addition to the direct medical costs, diabetes reduces the labor and productivity of patients [18]-[20]. In the United Sates, the total cost of diabetes was estimated at $\$ 245$ billion in 2012 [21]. A large part of the medical cost incurred by diabetic patients

Table 1. Number of hospitals joined the DPC/PDPS and beds by hospital size.

\begin{tabular}{|c|c|c|c|c|c|c|c|}
\hline \multicolumn{8}{|c|}{ Hospital sizes (number of beds) } \\
\hline Less than & 100 & $100-200$ & $200-300$ & $300-400$ & $400-500$ & $500+$ & Total \\
\hline \multicolumn{8}{|l|}{ Number of hospitals } \\
\hline $\begin{array}{c}\text { A: Joined the DPC/PDPS } \\
\text { Hospitals }^{*}\end{array}$ & 179 & 338 & 304 & 252 & 153 & 270 & 1496 \\
\hline B: All general hospitals ${ }^{* *}$ & 3126 & 2350 & 769 & 569 & 569 & 415 & 7528 \\
\hline $\mathrm{A} / \mathrm{B}(\%)$ & $5.7 \%$ & $14.4 \%$ & $39.5 \%$ & $44.3 \%$ & $26.9 \%$ & $65.1 \%$ & $19.9 \%$ \\
\hline \multicolumn{8}{|l|}{ Total number of beds } \\
\hline $\begin{array}{c}\text { C: Joined the DPC/PDPS } \\
\text { Hospitals }\end{array}$ & 11,924 & 50,581 & 75,291 & 86,277 & 67,459 & 183,499 & 47,4981 \\
\hline D: All general hospitals ${ }^{* *}$ & 116,262 & 193,237 & 111,703 & 139,231 & 102,341 & 236,611 & 899,385 \\
\hline $\mathrm{C} / \mathrm{D}(\%)$ & $10.3 \%$ & $26.2 \%$ & $67.4 \%$ & $62.0 \%$ & $65.9 \%$ & $77.6 \%$ & $52.8 \%$ \\
\hline
\end{tabular}

Source: DPC Evaluation Division [6]; $:$ : As of April 2013; ${ }^{* *}: 2011$ Survey Data. 
is determined by LOS. However, LOS for diabetic patients has not been widely studied, and until recently, only a few studies [22] [23] had been conducted on this issue in Japan. Nawata and Kawabuchi [5] [24] [25] analyzed the LOS of type 2 diabetes patients. These studies found there were surprisingly large differences in average length of stay (ALOS) among hospitals, even after eliminating the effects of patients' characteristics for both educational hospitalization (patients join programs to improve their lifestyle) and regular medical treatments. However, the effects of the DPC/PDPS revisions on individual hospitals were not analyzed in these studies. It is necessary and important to analyze the behaviors of individual hospitals and give hospitals proper medical and managerial advice and assistance in using medical information more efficiently.

In this paper, we analyze the effects of the 2010 revision (completed April 2010) on LOS of type 2 diabetes patients (DPC code: 100070xxxxxx0x) in individual hospitals. We consider not only ALOS but also the variance at individual hospitals. The Box-Cox transformation model [26] (BC model) under heteroscedasticity of error terms was used in the analysis. Sakia [27] and Hossain [28] have presented good summaries of the $\mathrm{BC}$ model, including empirical examples. The maximum likelihood estimator (BC MLE), which maximizes the likelihood function under the normality assumption, is usually used for the estimation of the BC model. However, the BC MLE cannot be generally consistent, and has large biases, especially under heteroscedasticity of error terms [29]. Heteroscedasticity is a very important problem in the BC model, as was mentioned even in the original paper by Box and Cox [26]. The variances of LOS are often very different among hospitals. Therefore, we use an estimator that is robust with respect to heteroscedasticity for analysis of the LOS of type 2 diabetes patients. A dataset of 18,641 patients collected from 51 general hospitals was used. Since we evaluated not only ALOS but also variance within hospitals, selected hospitals had at least 50 patients both before and after the 2010 revision.

\section{Model}

\subsection{BC Model}

Suppose that the LOS of patient $j$ in hospital $i$ is given by the BC model:

$$
\begin{gathered}
z_{i j}=\left(t_{i j}^{\lambda}-1\right) / \lambda \text { if } \lambda \neq 0, \quad z_{i j}=\log \left(t_{i j}\right) \text { if } \lambda=0, \\
z_{i j}=x_{i j}^{\prime} \beta+u_{i j}, i=1,2, \cdots, k, \quad j=1,2, \cdots, n_{i}
\end{gathered}
$$

where $t_{i j}$ is LOS; $\lambda$ is the transformation parameter; $x_{i j}$ and $\beta$ are the vectors of the explanatory variables and coefficients; $k$ is the number of hospitals; $n_{i}$ is the number of patients in hospital $i$ and $n=\sum n_{i}$, respectively. We assume that $k \rightarrow \infty$ and $n_{i}=o(n)$ for all $i$. Since we consider two periods, before and after the 2010 revision, $u_{i j}$ is a random variable distribution with mean 0 and variance $\sigma_{\mathrm{it}}^{2}, t=1,2$, where $t=1$ and $t=2$ denote periods before and after the revision, respectively.

\subsection{A Consistent Estimator under Heteroscedasticity}

$$
\begin{gathered}
M_{n}(\theta)=\sum_{i, j} m_{i j}(\theta), \\
m_{i j}(\theta)=-\frac{1}{\lambda \sigma^{2}}\left[\left\{\frac{\left(\lambda x_{i j}^{\prime} \beta+1\right) \log \left(\lambda x_{i j}^{\prime} \beta+1\right)}{\lambda}-x_{i j}^{\prime} \beta\right\}\left(z_{i j}-x_{i j}^{\prime} \beta\right)+\log \left(\lambda x_{i j}^{\prime} \beta+1\right)\right. \\
\left.+\frac{\lambda\left(z_{i j}-x_{i j}^{\prime} \beta\right)^{3}}{\lambda x_{i j}^{\prime} \beta+1}\right]+\frac{z_{i j}-x_{i j}^{\prime} \beta}{\lambda x_{i j}^{\prime} \beta+1} \text { if } \lambda \neq 0, \\
m_{i j}(\theta)=\lim _{\lambda \rightarrow 0} m_{i j}(\theta)=-\frac{1}{\sigma^{2}}\left(z_{i j}-x_{i j}^{\prime} \beta\right)^{3} \text { if } \lambda=0, \\
\sum x_{i j}\left(z_{i j}-x_{i j}^{\prime} \beta\right)=0, \text { and } \sigma^{2}=\sum_{i, j} \frac{\left(z_{i j}-x_{i j}^{\prime} \beta\right)^{2}}{n} .
\end{gathered}
$$


where $\theta^{\prime}=\left(\lambda, \beta^{\prime}, \sigma^{2}\right)$. If $E\left(u_{i j} \mid x_{i j}\right)=E\left(u_{i j}^{3} \mid x_{i j}\right)=0$, we get $E\left[M_{n}\left(\lambda_{0}, \beta_{0}, \sigma^{2}\right)\right]=0$ where $\left(\lambda_{0}, \beta_{0}^{\prime}\right)$ are true parameter values, and the estimators of $\lambda$ and $\beta$ obtained by Equation (2) are consistent from the same argument of Nawata [30]. When $\lambda=0, \quad \lim _{\lambda \rightarrow 0} m_{i j}(\theta)=-\frac{1}{\sigma^{2}}\left(z_{i j}-x_{i j}^{\prime} \beta\right)^{3}+\left(z_{i j}-x_{i j}^{\prime} \beta\right)$. However, $\sum_{i, j}\left(z_{i j}-x_{i j}^{\prime} \beta\right)=0$ if the model contains a constant term. Therefore, it usually becomes the third-moment restriction estimator of Nawata [31]. Let $\hat{\theta}_{N}^{\prime}=\left(\hat{\lambda}_{N}, \hat{\beta}_{N}, \hat{\sigma}_{N}^{2}\right)$ be the consistent root, $\bar{\sigma}^{2}=\lim _{n \rightarrow \infty} \frac{1}{n} \sum_{i, j} \sigma_{i j}^{2}$ and $\theta_{0}=\left(\lambda_{0}, \beta_{0}, \bar{\sigma}^{2}\right)$. The asymptotic distribution of this estimator $\hat{\theta}_{N}$ is given by

$$
\sqrt{n}\left(\hat{\theta}_{N}-\theta_{0}\right) \rightarrow N\left(0, A^{-1} B\left(A^{\prime}\right)^{-1}\right)
$$

where $A=-\left.p \lim _{n \rightarrow \infty} \frac{1}{n} \frac{\partial \xi}{\partial \theta}\right|_{\theta_{0}}, \quad \xi(\theta)^{\prime}=\left[M_{n}(\theta), \sum_{i, j}\left(z_{i j}-x_{i j}^{\prime} \beta\right) x_{i j}^{\prime}, \sum_{i, j}\left(y_{i j}-x_{i j}^{\prime} \beta\right)^{2}-n \bar{\sigma}^{2}\right]$,

$$
B=\lim _{n \rightarrow \infty} \frac{1}{n} \sum_{i, j} E\left[\left.\left.\frac{\partial \varsigma_{i j}}{\partial \theta}\right|_{\theta_{0}} \frac{\partial \varsigma_{i j}}{\partial \theta^{\prime}}\right|_{\theta_{0}}\right] \text {, and } \varsigma_{i j}\left(\theta_{0}\right)^{\prime}=\left[m_{i j}\left(\theta_{0}\right), x_{i j}^{\prime} u_{i j}, u_{i j}^{2}-\bar{\sigma}^{2}\right] .
$$

\section{2010 DPC/PDPS Revision for Diabetes and Data}

\subsection{DPC/PDPS Revision for Diabetes}

A revision of the DPC/PDPS was completed in April 2010, during the sample period. The daily payments to hospitals before and after the 2010 revision (DPC code: 100070xxxxxx0x) are listed in Table 2. Although Japanese medical payments are measured in points (hospitals are paid 10 yen per point), we use yen for convenience. In the 2010 revision, payment for the eighth day was increased 5240 yen, but daily payments for the first to the seventh days were reduced by 990 yen, and after the ninth day, the reduction was 1160 yen (if LOS was longer than 29 days, payments were determined on a conventional fee-for-service basis). As a result, payment was reduced 12,440 yen or $3.5 \%$ for a LOS of 16 days.

\subsection{Data}

We used the dataset managed by the Department of Health Care Economics at the Tokyo Medical and Dental University. Various information concerning patients' conditions, medical costs and treatments were available. In the case of diabetes, the dataset contains information on 27,861 patients, collected from July 2008 to March 2012 with the cooperation of various hospitals (currently, the dataset is the latest one and was updated in 2015). The DPC code for 22,430 patients (about $80 \%$ of all patients) was 100070xxxxxx0x (type 2 diabetes patient without diabetic ketoacidosis and secondary diseases). For details, see Nawata and Kawabuchi [24]. We used the data of patients: 1) who were treated in clinical departments that mainly treat diabetes; 2) whose primary disease and the disease that caused hospitalization were diabetes; 3 ) who had not received operations; and 4) whose purpose for hospitalization was joining an educational program or receiving regular medical care. Since we were evaluating the effects of the 2010 revision and analyzing variance of LOS in hospitals, we used the data

Table 2. Daily payments before and after 2010 revision (DPC code: 100070xxxxxx0x).

\begin{tabular}{cccc}
\hline \multicolumn{3}{c}{ LOS } \\
\hline Before 2010 & $1-7$ days & $8-15$ days & $16-29$ days \\
& 25,470 & 19,240 & \\
After 2010 & $1-8$ days & & $16-29$ days \\
& 24,480 & $9-15$ days & 15,190 \\
\hline
\end{tabular}


Table 3. LOS by hospitals.

\begin{tabular}{|c|c|c|c|c|c|c|c|c|c|c|c|c|c|}
\hline \multirow{2}{*}{ HP } & \multicolumn{3}{|c|}{ Before 2010} & \multicolumn{3}{|c|}{ After 2010} & \multirow{2}{*}{ HP } & \multicolumn{3}{|c|}{ Before 2010} & \multicolumn{3}{|c|}{ After 2010} \\
\hline & ALOS & SD & $\mathrm{N}$ & ALOS & SD & $\mathrm{N}$ & & ALOS & SD & $\mathrm{N}$ & ALOS & SD & $\mathrm{N}$ \\
\hline 1 & 14.7 & 5.9 & 312 & 14.6 & 5.6 & 315 & 27 & 10.2 & 4.0 & 160 & 10.2 & 3.3 & 219 \\
\hline 2 & 18.0 & 12.8 & 213 & 16.0 & 7.7 & 249 & 28 & 14.1 & 5.0 & 240 & 13.3 & 6.3 & 300 \\
\hline 3 & 27.5 & 15.6 & 138 & 25.9 & 11.6 & 133 & 29 & 15.9 & 6.9 & 112 & 15.8 & 6.0 & 154 \\
\hline 4 & 15.6 & 6.6 & 124 & 14.0 & 5.7 & 144 & 30 & 16.3 & 7.6 & 168 & 16.1 & 9.5 & 290 \\
\hline 5 & 16.4 & 9.7 & 188 & 15.8 & 6.9 & 131 & 31 & 23.5 & 12.1 & 153 & 21.8 & 16.1 & 176 \\
\hline 6 & 21.1 & 9.9 & 65 & 20.8 & 9.8 & 88 & 32 & 11.6 & 9.0 & 223 & 11.6 & 5.2 & 192 \\
\hline 7 & 14.6 & 9.7 & 53 & 13.6 & 11.3 & 96 & 33 & 22.0 & 10.4 & 181 & 22.6 & 11.0 & 176 \\
\hline 8 & 16.0 & 6.6 & 186 & 14.8 & 6.7 & 179 & 34 & 15.7 & 5.8 & 484 & 15.5 & 4.8 & 513 \\
\hline 9 & 15.0 & 6.0 & 61 & 16.4 & 7.7 & 104 & 35 & 16.0 & 6.5 & 108 & 15.6 & 7.5 & 109 \\
\hline 10 & 24.9 & 10.2 & 217 & 24.6 & 11.5 & 305 & 36 & 25.9 & 10.5 & 167 & 16.0 & 7.7 & 226 \\
\hline 11 & 16.2 & 6.8 & 64 & 14.1 & 6.5 & 129 & 37 & 18.8 & 12.3 & 80 & 14.6 & 10.8 & 186 \\
\hline 12 & 20.7 & 11.8 & 87 & 14.7 & 11.4 & 78 & 38 & 13.4 & 5.3 & 173 & 15.6 & 10.4 & 196 \\
\hline 13 & 11.7 & 9.6 & 240 & 9.6 & 4.9 & 311 & 39 & 15.6 & 10.3 & 132 & 15.9 & 10.1 & 99 \\
\hline 14 & 12.8 & 6.5 & 72 & 12.4 & 5.4 & 96 & 40 & 17.8 & 10.3 & 301 & 16.0 & 6.8 & 312 \\
\hline 15 & 14.0 & 11.0 & 74 & 14.2 & 7.5 & 70 & 41 & 33.5 & 23.4 & 332 & 43.6 & 25.6 & 225 \\
\hline 16 & 13.8 & 4.0 & 161 & 13.9 & 4.1 & 211 & 42 & 16.9 & 10.7 & 82 & 26.9 & 25.3 & 99 \\
\hline 17 & 16.1 & 4.9 & 118 & 16.0 & 5.8 & 136 & 43 & 15.1 & 5.7 & 138 & 19.4 & 13.2 & 190 \\
\hline 18 & 12.1 & 10.0 & 246 & 11.7 & 9.6 & 246 & 44 & 9.5 & 3.7 & 221 & 9.8 & 4.5 & 247 \\
\hline 19 & 16.6 & 7.5 & 161 & 17.8 & 10.0 & 199 & 45 & 17.3 & 9.3 & 266 & 17.5 & 9.5 & 186 \\
\hline 20 & 14.8 & 7.6 & 227 & 13.0 & 5.6 & 223 & 46 & 14.2 & 4.4 & 178 & 14.3 & 4.5 & 219 \\
\hline 21 & 13.5 & 10.3 & 204 & 17.2 & 14.0 & 138 & 47 & 16.0 & 6.5 & 94 & 19.8 & 9.0 & 124 \\
\hline 22 & 9.4 & 3.7 & 136 & 11.0 & 6.0 & 206 & 48 & 13.2 & 5.8 & 505 & 13.6 & 6.8 & 740 \\
\hline 23 & 17.3 & 11.0 & 135 & 17.0 & 8.8 & 136 & 49 & 19.7 & 9.1 & 123 & 19.9 & 7.6 & 127 \\
\hline 24 & 21.0 & 12.5 & 69 & 18.3 & 9.7 & 166 & 50 & 11.3 & 6.3 & 60 & 11.8 & 3.9 & 53 \\
\hline 25 & 16.5 & 8.7 & 231 & 14.8 & 8.5 & 170 & 51 & 25.4 & 12.9 & 68 & 25.6 & 13.0 & 151 \\
\hline 26 & 14.8 & 10.7 & 60 & 15.1 & 6.4 & 102 & All & 16.7 & 10.8 & 8591 & 16.3 & 10.9 & 9870 \\
\hline
\end{tabular}

of patients in 51 hospitals (Hp1-51) where there were more than 50 patients both before (July 2008-March 2010) and after (April 2010-March 2012) the revision. There were 18,475 patients in these hospitals. Table 3 presents a summary of LOS by hospitals. Before the 2010 revision, the number of patients was 8591 and the ALOS at all the hospitals was 16.7 days, with a standard deviation (SD) of 10.8 days. Among hospitals, the shortest ALOS was 9.4 days (HP22) and the longest was 33.5 days (HP41). As to the SD, the smallest was 3.7 days (HP22) and the largest was 23.4 days (HP41). After the 2010 revision, the number of patients was 9870 and the ALOS for these patients was 16.3 days with a SD 10.9 days. The shortest ALOS among hospitals was 9.6 days (HP13) and longest was 43.6 days (HP41). The smallest SD was 3.3 days (HP26) and the largest was 25.6 days (HP41). There were surprisingly large differences not only in ALOS but also in SD.

\section{Results of Estimation}

\subsection{Estimation of the BC Model}

We chose the following as explanatory variables. The Female Dummy (0: male, 1 : female) was used for gender. The proportions of male and female patients were $58.7 \%$ and $41.3 \%$, respectively. Since LOS tends to increase with patient age, we used Age as an explanatory variable. The average age of the patients was 62.9, with a SD of 13.6. During the sample period, direct medical payments by patients changed at age 70 ( $30 \%$ for those younger than 70 , and $10 \%$ for those 70 or older). Therefore, we added an Age-70 Dummy (1: if 70 or older, 0: otherwise). Among diabetic patients, many were hospitalized to join an educational program for managing diabetes 
rather than to receive regular medical treatment. For the purpose of hospitalization, we used the Education Dummy (joining educational program: 1, otherwise: 0 ). The proportion of patients joining an educational program was $35.5 \%$. Other explanatory variables representing the characteristics of patients included Comorbidities (number of Comorbidities), Complications (numbers of complications), Acute Hospitalization Dummy (acute hospitalization: 1, otherwise: 0), Outpatient Dummy (outpatient of the same hospital before hospitalization: 1, otherwise: 0), and Other Hospital Dummy (introduced by another hospital: 1, otherwise: 0), Discharged Place dummy (return to home: 1, otherwise: 0), Winter dummy (hospitalized from December to February: 1, otherwise: 0), and Summer dummy (hospitalized in July or August: 1, otherwise: 0). Among our study subjects, $85.4 \%$ of patients had comorbidities, and among those with comorbidities, the average number was 2.93 . A total of $42.1 \%$ of patients had complications, and those patients had 2.17 complications on average. The proportion of the acute hospitalization patients, outpatients of the same hospital before hospitalization, patients introduced by other hospitals, patients returned to home, patients hospitalized in the winter, and patients hospitalized in the summer were $13.1 \%, 85.7 \%, 44.1 \%, 77.0 \%, 22.2 \%$, and $21.5 \%$, respectively.

Figure 1 shows the relation between LOS and number of patients. Many patients were discharged from the hospital on the eighth day (one week hospitalization). Therefore, we added a Day-8 dummy (left on the eighth day: 1, otherwise: 0). Furthermore, if the LOS exceeded the Specific Hospitalization Period (29 days), the medical payment switched to a conventional fee-for-service system. Hence, we added an Over-Specific-Hospitalization-Period Dummy (LOS over 29 days: 1, otherwise: 0 ), and found that $7.9 \%$ of patients, relatively small number of patients, stayed over 29 days. For principal disease classification, dummy variables based on the ICD-10 code E11.9 (without complications) were used. In terms of classification, $31.9 \%$ of patients had diseases classified under E11.9, 5.9\% had diseases under E11.2 (with kidney complications), 7.2\% had diseases under E11.3 (with ophthalmic complications), $6.2 \%$ had diseases under E11.4 (with neurological complications), $0.8 \%$ had diseases under E11.5 (with circulatory complications), 14.2\% had diseases under E11.6 (with other specified complications), and 32.0\% had diseases under E11.7 (with multiple complications). To evaluate the effects of the 2010 revisions on individual hospitals, 51 Hospital dummies and products of hospital dummies, and a 2010 Revision dummy (after 2010 revision: 1, otherwise: 0 ) were used. The constant term was not used in the model.

As a result, $x_{i j}^{\prime} \beta_{1}$ of Equation (1) became

$$
\begin{aligned}
x_{i j}^{\prime} \beta_{1}= & \beta_{1} \text { Female Dummy }+\beta_{2} \text { Age }+\beta_{3} \text { Age-70 Dummy }+\beta_{4} \text { Education Dummy }+\beta_{5} \text { Comorbidities } \\
& +\beta_{6} \text { Complications }+\beta_{7} \text { Acute Hospitalization Dummy }+\beta_{8} \text { Outpatient Dummy } \\
& +\beta_{11} \text { Other Hospital Dummy }+\beta_{12} \text { Discharged Place Dummy }+\beta_{13} \text { Winter Dummy } \\
& +\beta_{14} \text { Day- } 8 \text { Dummy }+\beta_{15} \text { Over-Specific-Hospitalization-Period Dummy } \\
& +\sum_{\ell} \beta_{\ell} \ell \text {-th Principle Disease Dummy }+\sum_{i} \beta_{i} i \text {-th Hospital Dummy } \\
& +\sum_{j} \beta_{j} j \text {-th Hospital Dummy } \times 2010 \text { Revision Dummy }
\end{aligned}
$$

The estimates of coefficients are presented in Table 4. The estimate for Age was positive and significant at the 5\% level; that implies LOS was longer if a patient was older. The Female and Age-70 Dummies were not significant, however, although Sittig, Friedel and Wasem [31] reported that gender affected medical costs of type 2 diabetes outpatients. We could not admit the effects of these variables. The estimate for the Educational Dummy was negative and significant at the $1 \%$ level, implying that LOS was shorter if the purpose of hospitalization was not medical treatment. The estimates for the Comorbidities and Complications were positive and significant at the $1 \%$ level. As expected, comorbidities and complications made LOS longer. The estimates for Acute Hospitalization and Other Hospital Dummies were also positive and significant at the $1 \%$ level, and these variables made LOS longer. However, the estimates for Outpatient and Discharged Place Dummies were not significant, and we could not find any evidence that LOS depends on these variables.

The estimate for the Winter Dummy was negative and significant at the 5\% level, while the estimate of Summer Dummy was not significant. This implies that the LOS became shorter in the winter but not in summer. The estimates of Day-8 and Over-Specific-Hospitalization-Period Dummies were significant at the $1 \%$ level and these variables affected the LOS. Since the Japanese society and hospital administration are usually operated a weekly base. Moreover, the daily payment increased on the eighth day, the incentive to discharge the patients on the eighth day became stronger by the revision. The estimate of Over-Specific-Hospitalization-Period Dummy is 5.386, which was much larger than the estimates of other variables. The daily payments become the conventional 
Table 4. Estimates of coefficients.

\begin{tabular}{|c|c|c|c|c|c|c|c|}
\hline Variable & Coefficient & Std. Error & $\mathrm{t}$-Statistic & Variable & Coefficient & Std. Error & $\mathrm{t}$-Statistic \\
\hline lambda & 0.5403 & 0.0009 & $589.847^{* *}$ & HP16 & 5.0355 & 0.1532 & $32.878^{* *}$ \\
\hline Female & 0.0433 & 0.0240 & 1.802 & HP17 & 5.5338 & 0.1628 & $33.996^{* *}$ \\
\hline Age & 0.0033 & 0.0015 & $2.182^{*}$ & HP18 & 4.1029 & 0.1585 & $25.891^{* *}$ \\
\hline Age-70 & 0.0713 & 0.0391 & 1.823 & HP19 & 5.4522 & 0.1690 & $32.263^{* *}$ \\
\hline Education & -0.2081 & 0.0304 & $-6.839^{* *}$ & HP20 & 5.0085 & 0.1513 & $33.096^{* *}$ \\
\hline Secondary & 0.1337 & 0.0093 & $14.366^{* *}$ & HP21 & 4.3330 & 0.1785 & $24.273^{* *}$ \\
\hline Complications & 0.1908 & 0.0100 & $19.177^{* *}$ & HP22 & 4.5306 & 0.1490 & $30.414^{* *}$ \\
\hline Acute & 0.1333 & 0.0473 & $2.816^{* *}$ & HP23 & 4.2638 & 0.1974 & $21.596^{* *}$ \\
\hline Outpatient & 0.0100 & 0.0480 & 0.209 & HP24 & 5.5598 & 0.2183 & $25.469^{* *}$ \\
\hline Other Hospital & 0.1222 & 0.0286 & 4.277 & HP25 & 5.0361 & 0.1649 & $30.546^{* *}$ \\
\hline Discharged & 0.0063 & 0.0326 & 0.194 & HP26 & 4.9145 & 0.2354 & $20.878^{* *}$ \\
\hline Winter & -0.0598 & 0.0298 & $-2.009^{*}$ & HP27 & 3.8270 & 0.1461 & $26.197^{* *}$ \\
\hline Summer & -0.0321 & 0.0295 & -1.086 & HP28 & 4.9870 & 0.1367 & $36.490^{* *}$ \\
\hline Day-8 & -1.3952 & 0.0309 & $-45.142^{* *}$ & HP29 & 4.7700 & 0.1877 & $25.413^{* *}$ \\
\hline Over Specific & 5.3864 & 0.0611 & $88.156^{* *}$ & HP30 & 5.5689 & 0.1721 & $32.368^{* *}$ \\
\hline E112 & 0.0887 & 0.0574 & 1.546 & HP31 & 6.0447 & 0.1786 & $33.836^{* *}$ \\
\hline E113 & 0.0460 & 0.0473 & 0.973 & HP32 & 4.1261 & 0.1686 & $24.466^{* *}$ \\
\hline E114 & 0.0560 & 0.0586 & 0.957 & HP33 & 5.8173 & 0.1640 & $35.473^{* *}$ \\
\hline E115 & 0.3477 & 0.1392 & $2.497^{*}$ & HP34 & 5.3623 & 0.1285 & $41.731^{* *}$ \\
\hline E116 & 0.1177 & 0.0422 & $2.789^{* *}$ & HP35 & 5.5046 & 0.2237 & $24.611^{* *}$ \\
\hline E117 & 0.2067 & 0.0316 & $6.542^{* *}$ & HP36 & 6.0846 & 0.1769 & $34.393^{* *}$ \\
\hline \multicolumn{2}{|c|}{ Hospital Dummies } & & & HP37 & 5.3987 & 0.2594 & $20.815^{* *}$ \\
\hline HP1 & 4.9597 & 0.1385 & $35.809^{* *}$ & HP38 & 4.7260 & 0.1587 & $29.780^{* *}$ \\
\hline HP2 & 5.5065 & 0.1731 & $31.811^{* *}$ & HP39 & 4.3024 & 0.1931 & $22.275^{* *}$ \\
\hline HP3 & 6.2319 & 0.2155 & $28.912^{* *}$ & HP40 & 5.5132 & 0.1396 & $39.505^{* *}$ \\
\hline HP4 & 5.4010 & 0.1746 & $30.927^{* *}$ & HP41 & 6.8775 & 0.1834 & $37.503^{* *}$ \\
\hline HP5 & 5.2361 & 0.1530 & $34.231^{* *}$ & HP42 & 4.9355 & 0.2670 & $18.487^{* *}$ \\
\hline HP6 & 5.5937 & 0.2138 & $26.161^{* *}$ & HP43 & 5.2174 & 0.1718 & $30.371^{* *}$ \\
\hline HP7 & 4.3014 & 0.2380 & $18.075^{* *}$ & HP44 & 3.7187 & 0.1442 & $25.781^{* *}$ \\
\hline HP8 & 5.3762 & 0.1398 & $38.456^{* *}$ & HP45 & 5.3576 & 0.1500 & $35.724^{* *}$ \\
\hline HP9 & 4.7243 & 0.2187 & $21.604^{* *}$ & HP46 & 4.8354 & 0.1422 & $33.994^{* *}$ \\
\hline HP10 & 6.0211 & 0.1629 & $36.965^{* *}$ & HP47 & 5.0981 & 0.1803 & $28.268^{* *}$ \\
\hline HP11 & 5.5559 & 0.2245 & $24.745^{* *}$ & HP48 & 4.5541 & 0.1360 & $33.475^{* *}$ \\
\hline HP12 & 5.7706 & 0.2064 & $27.960^{* *}$ & HP49 & 5.6760 & 0.1890 & $30.037^{* *}$ \\
\hline HP13 & 4.2153 & 0.1587 & $26.560^{* *}$ & HP50 & 4.1602 & 0.2166 & $19.208^{* *}$ \\
\hline HP14 & 4.4664 & 0.1909 & $23.403^{* *}$ & HP51 & 6.3955 & 0.2584 & $24.749^{* *}$ \\
\hline HP15 & 4.6902 & 0.2403 & $19.515^{* *}$ & & & & \\
\hline
\end{tabular}




\begin{tabular}{|c|c|c|c|c|c|c|c|}
\hline \multicolumn{4}{|c|}{ Hospital Dummies $\times 2010$ Revision Dummy } & \multirow{2}{*}{$\begin{array}{l}\text { HP27 } \\
\text { HP28 }\end{array}$} & \multirow{2}{*}{$\begin{array}{l}-0.0944 \\
-0.2987\end{array}$} & \multirow{2}{*}{$\begin{array}{l}0.1027 \\
0.0924\end{array}$} & \multirow{2}{*}{$\begin{array}{l}-0.919 \\
-3.234^{* *}\end{array}$} \\
\hline HP1 & -0.0290 & 0.1114 & -0.260 & & & & \\
\hline HP2 & -0.4500 & 0.1626 & -2.768 & HP29 & 0.3228 & 0.1938 & 1.666 \\
\hline HP3 & -0.2309 & 0.2677 & -0.863 & HP30 & -0.6617 & 0.1697 & $-3.900^{* *}$ \\
\hline HP4 & -0.5969 & 0.1654 & $-3.608^{* *}$ & HP31 & -0.2084 & 0.2036 & -1.024 \\
\hline HP5 & -0.3459 & 0.1537 & $-2.250^{*}$ & HP32 & 0.0838 & 0.1653 & 0.507 \\
\hline HP6 & 0.0503 & 0.2412 & 0.209 & HP33 & -0.0120 & 0.1794 & -0.067 \\
\hline HP7 & 0.1024 & 0.2622 & 0.391 & HP34 & -0.1018 & 0.0818 & -1.245 \\
\hline HP8 & -0.1853 & 0.1559 & -1.189 & HP35 & -0.1384 & 0.2979 & -0.465 \\
\hline HP9 & 0.4214 & 0.2382 & 1.770 & HP36 & -1.1478 & 0.1670 & $-6.871^{* *}$ \\
\hline HP10 & -0.1031 & 0.1579 & -0.653 & HP37 & -1.2783 & 0.2736 & $-4.672^{* *}$ \\
\hline HP11 & -0.6156 & 0.2367 & $-2.600^{* *}$ & HP38 & 0.2422 & 0.1479 & 1.638 \\
\hline HP12 & -0.8272 & 0.2582 & $-3.203^{* *}$ & HP39 & -0.0798 & 0.2287 & -0.349 \\
\hline HP13 & -0.5643 & 0.1293 & $-4.364^{* *}$ & HP40 & -0.1807 & 0.1182 & -1.529 \\
\hline HP14 & -0.1217 & 0.2031 & -0.600 & HP41 & 0.5635 & 0.2542 & $2.216^{*}$ \\
\hline HP15 & 0.2128 & 0.2922 & 0.728 & HP42 & 1.1964 & 0.3702 & $3.232^{* *}$ \\
\hline HP16 & -0.0277 & 0.1184 & -0.234 & HP43 & 0.4446 & 0.1683 & $2.642^{* *}$ \\
\hline HP17 & -0.2487 & 0.1501 & -1.657 & HP44 & -0.0187 & 0.1219 & -0.154 \\
\hline HP18 & -0.0850 & 0.1532 & -0.555 & HP45 & -0.1698 & 0.1448 & -1.173 \\
\hline HP19 & 0.2648 & 0.1567 & 1.689 & HP46 & -0.1021 & 0.1022 & -0.999 \\
\hline HP20 & -0.4325 & 0.1255 & $-3.447^{* *}$ & HP47 & 0.8998 & 0.1945 & $4.626^{* *}$ \\
\hline HP21 & 0.7828 & 0.2149 & $3.643^{* *}$ & HP48 & 0.1096 & 0.0821 & 1.335 \\
\hline HP22 & -0.0609 & 0.1236 & -0.493 & HP49 & 0.2342 & 0.1915 & 1.223 \\
\hline HP23 & 0.1726 & 0.2187 & 0.789 & HP50 & 0.4020 & 0.2503 & 1.606 \\
\hline HP24 & 0.0932 & 0.2332 & 0.400 & HP51 & -0.6491 & 0.2712 & $-2.393^{* *}$ \\
\hline HP25 & -0.1855 & 0.1583 & -1.172 & $\mathrm{R} 2$ & & 0.6010 & \\
\hline HP26 & 0.2394 & 0.2320 & 1.032 & & & & \\
\hline
\end{tabular}

${ }^{*}$ Significant at the $5 \%$ level; ${ }^{* *}$ Significant at the $1 \%$ level.

number of patients

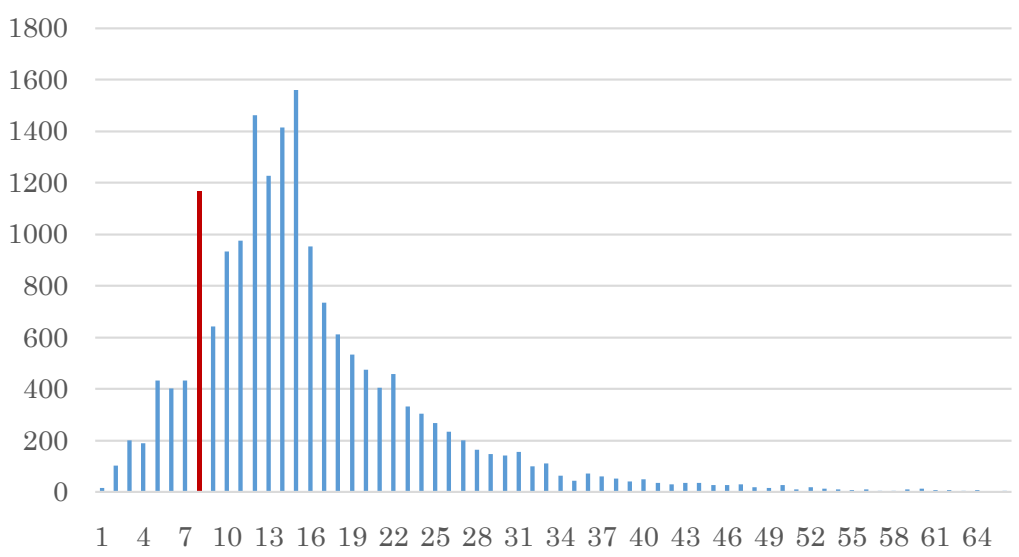

LOS

Figure 1. Distribution of LOS. 
fee-for-service over the Specific Hospitalization Period, and daily payment does not decrease anymore. In other words, the incentives for hospitals to discharge patients become very weak once their LOS exceeds the Specific Hospitalization Period. This is one problem of the DPC/PDPS and should be revised in the future. With respect to the principal disease classifications, the estimate for the E11.5, E11.6 and E11.7 Dummy were positive and significant at the 5\% and $1 \%$ levels, but none of the other estimates was significant at the $5 \%$ level. There were surprisingly large differences among the estimates of Hospital Dummies. The largest was 6.878 (HP41) and the smallest was 3.718 (HP44), and the difference was 3.159. This implies that there were very large differences in ALOS among hospitals even after eliminating the effects of patients' conditions and principal diseases. For the products of hospital dummies and after 2010 dummy, estimates of 5 hospitals were positive and significant at the $5 \%$ level, and 12 hospitals were negative and significant at the $5 \%$ level. The correlation coefficients of estimates of Hospital Dummies and (Hospital Dummies $\times 2010$ Revision Dummy) was -0.283 and significant at the $5 \%$ level. This implies that although the amount of reduction was rather small, the 2010 revision reduced the ALOS of hospitals and ALOS became shorter if the ALOS was longer before 2010 revision.

\subsection{Estimation of Variances}

The estimates of $\sigma_{\mathrm{it}}^{2}, \hat{\sigma}_{\mathrm{it}}^{2}$, are represented are Table 5. There were large differences in $\hat{\sigma}_{\mathrm{it}}^{2}$, and the feasibility of the proposed model was strongly suggested. Before the 2010 revision $(t=1)$, the variance of all patients was

Table 5. Estimates of variances.

\begin{tabular}{|c|c|c|c|c|c|c|c|}
\hline Hospital & Before 2010 & After 2010 & Change & Hospital & Before 2010 & After 2010 & Change \\
\hline HP1 & 1.8525 & 2.0192 & & HP27 & 1.0078 & 0.7483 & - \\
\hline HP2 & 3.4624 & 2.5160 & - & HР28 & 0.8956 & 1.4398 & + \\
\hline HP3 & 4.4171 & 5.3318 & & HР29 & 2.5062 & 2.3284 & \\
\hline HP4 & 1.9915 & 1.6496 & & HP30 & 2.7928 & 3.5018 & \\
\hline HP5 & 1.8005 & 1.8262 & & HP31 & 2.8122 & 4.0721 & + \\
\hline HP6 & 2.0266 & 2.4218 & & HP32 & 3.3642 & 2.3320 & - \\
\hline HP7 & 2.3027 & 2.3252 & & HP33 & 2.5035 & 3.2486 & \\
\hline HP8 & 1.8139 & 2.5299 & + & HP34 & 1.7304 & 1.5056 & \\
\hline HP9 & 2.1640 & 2.2605 & & HP35 & 2.4182 & 2.4378 & \\
\hline HP10 & 2.9890 & 3.2382 & & HР36 & 2.7703 & 2.4119 & \\
\hline HP11 & 2.6192 & 2.0516 & & HP37 & 4.2005 & 4.1738 & \\
\hline HP12 & 2.5309 & 2.9264 & & HP38 & 1.7148 & 2.2104 & \\
\hline HP13 & 2.8666 & 1.4672 & - & HР39 & 3.1063 & 2.8551 & \\
\hline HP14 & 1.5599 & 1.9072 & & HP40 & 2.4138 & 1.8425 & - \\
\hline HP15 & 3.3664 & 2.8519 & & HP41 & 6.7657 & 9.8720 & + \\
\hline HP16 & 1.2089 & 1.0879 & & HP42 & 4.7088 & 8.0843 & + \\
\hline HP17 & 1.5126 & 1.3256 & & HР43 & 2.0251 & 2.6085 & \\
\hline HP18 & 2.5097 & 3.2657 & + & HP44 & 1.5419 & 1.9425 & \\
\hline HP19 & 2.4621 & 1.8265 & - & HP45 & 2.2622 & 2.3140 & \\
\hline HP20 & 2.0720 & 1.4671 & - & HP46 & 1.0994 & 0.8914 & \\
\hline HP21 & 3.7532 & 3.8426 & & HP47 & 1.8231 & 2.2608 & \\
\hline HP22 & 1.0496 & 1.5535 & + & HР48 & 1.8224 & 2.3009 & + \\
\hline HP23 & 3.5357 & 2.9174 & & HР49 & 2.6600 & 1.8645 & - \\
\hline HP24 & 2.6411 & 2.7273 & & HP50 & 2.0894 & 1.5277 & \\
\hline HP25 & 3.0758 & 1.9885 & - & HP51 & 3.7629 & 2.8069 & \\
\hline HP26 & 2.4526 & 1.3691 & - & & & & \\
\hline
\end{tabular}

+: Variance significantly increased at 5\% level; -: Variance significantly decreased at 5\% level. 
2.493, the largest $\hat{\sigma}_{i 1}^{2}$ was 6.766 , and the smallest was 0.896 . After the 2010 revision $(t=2)$, the variance of all patients was 2.486 , the largest $\hat{\sigma}_{i 2}^{2}$ was 6.766 , and the smallest was 0.896 . Since we assume $k \rightarrow \infty$ and $n_{i}=o(n)$, the convergence rate of $\hat{\sigma}_{\mathrm{it}}^{2}$ is $1 / \sqrt{n_{i}}$ and slower than the convergence rate $(1 / \sqrt{n})$ of the estimators for the coefficients of explanatory variables other than hospital dummies, and (Hospital Dummies $\times 2010$ Revision Dummy). Furthermore, all hospital dummies were orthogonal with each other. Therefore, $\hat{\sigma}_{\mathrm{it}}^{2}$ become asymptotically independent, and we can use the standard $F$-test of variance for heteroscedasticity. For all patients, the $F$-statistic, from testing the change of variance in the periods before and after the 2010 revision, was $F$ $=0.998$ and not significant at the $5 \%$ level. The variance significantly decreased for 8 hospitals, but significantly increased for 10 hospitals at the $5 \%$ level. We could not find any clear evidence that the variance decreased after the 2010 revision.

\section{Discussion}

The introduction and revisions of the DPC/PDPS have affected behaviors of hospitals and patients in several different ways. The daily payments, which are the marginal revenue of the hospital, decrease as the LOS becomes longer. In other words, the DPC/PDPS is designed to give hospitals an incentive to reduce the LOS. Second, it has affected hospitals' reputation. The three periods determined by the DPC/PDPS represent the standard LOS, which were not clear to the public before. Moreover, various information regarding DPC hospitals, such as ALOS by hospital and DPC codes, was officially disclosed [32]. Since it has become possible to compare hospitals throughout the nation, the criticism for unnecessarily long LOS will likely become more serious as time passes. Reputation is considered very important. Despite the fact that joining the DPC/PDPS imposes financial and operational burdens on hospitals [5], most large hospitals joined the DPC/PDPS. Reputation is one reason why, because the public and patients tend to think DPC hospitals are better than non-DPC hospitals.

Third, DPC hospitals are required to computerize their medical information. This can help hospitals improve and standardize their medical treatments. These arguments suggest that while the introduction and revisions of the DPC/PDPS affect LOS, the effects are different depending on the type of patient. Hospitals have strong incentives to reduce LOS for patients with long hospitalizations, but the incentives are weak (or nonexistent) for patients with shorter LOS. Therefore, the effects of the introduction and revisions to hospitals might not be the same. Hospitals that have many long LOS patients (and therefore, long ALOS) are more likely to be affected. This means that the scattering of ALOS among hospitals becomes smaller.

Furthermore, hospitals try to reduce long LOS patients within hospitals and that makes variances of LOS within hospitals smaller. The proper use of medical information obtained by the joining DPC/PDPS will help hospitals to standardize medical practices within their facilities. This effect will become more apparent as time passes. Although we did not consider progress in medical technologies, it is possible that it would reduce both ALOS and variance within hospitals. All these arguments lead us to the same conclusion; that is, ALOS and variance of LOS within hospitals in the period after the 2010 revision should be smaller than those in the period before the 2010 revision.

The results of our study provided only limited support for these arguments. It is true that the ALOS became shorter, especially for the hospitals with long ALOS. However, the effects were marginal, with ALOS shortened only a small amount. Moreover, we could not find any evidence that variance of LOS within hospitals was reduced. The facts imply that the current DPC/PDPS did not work properly to improve and standardize the medical system. Introduction and modification of proper hospitalization schedules and clinical paths may be necessary, especially for hospitals with long ALOS and large variance of LOS. Incentives and advice on the effective use of medical information are absolutely necessary. The problems caused by the Specific Hospitalization Period should also be reviewed. These are subjects to be considered in further revisions of the DPC/PDPS.

\section{Conclusions}

In this paper, we consider an analysis of LOS of type 2 diabetes patients by the Box-Cox transformation model when variance differs among hospitals, and the number of hospitals increases to infinity. In the study, we evaluated effects of the 2010 revision of the DPC/PDPS, analyzing not only ALOS but also variance of LOS of individual hospitals. There were large differences among hospitals, and the feasibility of the proposed model was strongly supported. We then analyzed the dataset of 18,641 patients collected from 51 general hospitals that had 
at least 50 patients in the periods both before and after the 2010 revision.

The variables found to affect LOS were age, comorbidities, complications, acute hospitalization, introduced by other hospitals, winter, one-week hospitalization, specific hospitalization period, and principal diseases coded E11.5, E11.6 and E11.7. There were surprisingly large differences in both ALOS and variance of LOS among hospitals, even after eliminating effects of patients' conditions and principle diseases. Although the effect was marginal, the 2010 revision reduced ALOS, and this reduction increased for longer ALOS. On the other hand, we could not find any evidence that variance of LOS within hospitals became smaller. If the DPC/PDPS works properly and obtained information is correctly used, variance within hospitals should be smaller. The major goal of this study was to evaluate whether the DPC/PDPS worked properly or not. In the case of this disease, the answer seems to be no: the results of the study suggest that the DPC/PDPS did not work properly and the computerized information was not used effectively. Therefore, giving hospitals incentives and advice on the efficient use of medical information are necessary in future revisions of the DPC/PDPS. The problems with the Specific Hospitalization Period should also be reconsidered. It will be necessary to analyze other important types of diseases, such as cancer, to further evaluate the sustainability of the Japanese medical payment system.

In this study, we employed the Box-Cox transformation model. However, there are other types of models for analyzing LOS, and the selection of a proper model is very important in empirical analyses. Basu, Manning, Mullahy [33] compared log-transformation, gamma regression, Weibull regression and Cox [34] propotional hazard models in a Monte Carlo study. However, their study failed to determine the best model. These are subjects to be analyzed in future studies.

\section{Acknowledgements}

The Institutional Review Boards of the University of Tokyo (No. KE12-7) and Tokyo Medical and Dental University (No. 839) approved the use of this dataset. An earlier version of the paper was presented at the International Congress on Modelling and Simulation 2015 (MODSIM 2015) in the Gold Coast, Australia. We would like to thank an anonymous referee and the participants of the congress for their helpful comments. We also thank various hospitals for their sincere cooperation.

\section{References}

[1] Ministry of Health, Labour and Welfare, Ministry of Health (2015) The Japan Vision: Health Care 2035 Executive Summary.

[2] Nawata, K. (2015) Is the Japanese Medical System Sustainable? Journal of Health \& Medical Economics, 1, 1-2.

[3] Ministry of Health, Labour and Welfare (2015) Hesiei 25 nendo kokumin iryouhi. National Medical Expenditures, Fiscal Year 2013. (In Japanese)

[4] Nawata, K., Toyama, H., et al. (2009) Evaluation of the Inclusive Payment System Based on the Diagnosis Procedure Combination with Respect to Cataract Operations in Japan: A Comparison of Lengths of Hospital Stay and Medical Payments among Hospitals. Health, 1, 93-103. http://dx.doi.org/10.4236/health.2009.12016

[5] Nawata, K. and Kawabuchi, K. (2015) Evaluation of Length of Hospital Stay Joining Educational Programs for Type 2 Diabetes Mellitus Patients: Can We Control Medical Costs in Japan? Health, 7, 256-269. http://dx.doi.org/10.4236/health.2015.72030

[6] DPC Evaluation Division, Central Social Insurance Medical Council (2013) DPC taishou hyouin Junbi hyouin no gennjouni tsuite. Current Situations of DPC Hospitals and Preparing Hospitals, in Japanese.

[7] International Diabetes Foundation (2014) Diabetes Atlas. 6th Edition. http://www.idf.org/sites/default/files/Atlas-poster-2014 EN.pdf

[8] American Diabetes Association: ADA (2015) Complications. http://www.diabetes.org/

[9] Inoue, M., Iwasak, M., Otani, T., et al. (2006) Diabetes Mellitus and the Risk of Cancer. Archives of International Medicine, 166, 1871-1877. http://dx.doi.org/10.1001/archinte.166.17.1871

[10] Lesniowska, J., Schubert, A., Wojna, M., Skrzekowska-Baran I. and Fedyna, M. (2014) Costs of Diabetes and Its Complications in Poland. The European Journal of Health Economics, 15, 653-660. http://dx.doi.org/10.1007/s10198-013-0513-0

[11] Kudo, T., Fujino, Y., Matsuura, A., Ichimiya, Y., Kuwabara, K., Fujimori, K., et al. (2011) Prevalence of Type 2 Diabetes among Acute Inpatients and Its Impact on Length of Hospital Stay in Japan Diabetes Mellitus and the Risk of 
Cancer: Results from a Large-Scale Population-Based Cohort Study in Japan. Internal Medicine, 50, 405-411. http://dx.doi.org/10.2169/internalmedicine.50.4268

[12] Chereches, R.M., Litan, C.M., Zlati, A.M. and Bloom, J.R. (2012) Does Comorbid Depression Impact Diabetes Related Costs? Evidence from a Cross-Sectional Survey in a Low-Income Country. Journal of Mental Health Policy and Economics, 15, 127-138.

[13] Yeaw, J. (2014) Direct Medical Costs for Complications among Children and Adults with Diabetes in the US Commercial Setting. Applied Health Economics and Health Policy, 12, 219-230. http://dx.doi.org/10.1007/s40258-014-0086-9

[14] Zhuo X., Zhang, P., Barker, L., Albright, A., Thompson, T.J. and Gregg, E. (2014) The Lifetime Cost of Diabetes and Its Implications for Diabetes Prevention. Diabetes Care, 37, 2557-2564. http://dx.doi.org/10.2337/dc13-2484

[15] Nirantharakumar, K., Marshall, T., Kennedy, A., Narendran, P., Hemming, K. and Coleman, J.J. (2012) Hypoglycaemia Is Associated with Increased Length of Stay and Mortality in People with Diabetes Who Are Hospitalized. Diabetic Medicine, 29, e445-e448. http://dx.doi.org/10.1111/dme.12002

[16] Parappil, A., Depczynski, B., Collett, P. and Marks, G.B. (2010) Effect of Comorbid Diabetes on Length of Stay and Risk of Death in Patients Admitted with Acute Exacerbations of COPD. Respirology, 15, 918-922. http://dx.doi.org/10.1111/j.1440-1843.2010.01781.x

[17] Public Health Agency of Canada (2015) The Health and Economic Impacts of Diabetes. Chapter 3, Diabetes in Canada: Facts from a Public Health Perspective. http://www.phac-aspc.gc.ca/cd-mc/publications/diabetes-diabete/facts-figures-faits-chiffres-2011/chap3-eng.php

[18] Minor, T. (2011) The Effect of Diabetes on Female Labor Force Decision: New Evidence from the National Health Interview Survey. Health Economics, 20, 1468-1486. http://dx.doi.org/10.1002/hec.1685

[19] Sørensen, J. and Ploug, U.J. (2013) The Cost of Diabetes-Related Complications: Registry-Based Analysis of Days Absent from Work. Economic Research International, 2013, Article ID: 618039. http://dx.doi.org/10.1155/2013/618039

[20] Minor, T. (2013) An Investigation into the Effect of Type I and Type II Diabetes Duration on Employment and Wages. Economics and Human Biology, 11, 534-544. http://dx.doi.org/10.1016/j.ehb.2013.04.004

[21] American Diabetes Association (ADA) (2013) Economic Costs of Diabetes in the U.S. in 2012. Diabetes Care, 36, 1033-1046. http://dx.doi.org/10.2337/dc12-2625

[22] Mutou, K., Uchigata, Y. and Yamada, H. (1999) 18 sai miman hasshou IDDM kanja nonyuuin nissu ni kansuru chousa [Investigation on Hospitalization Days in Crisis of IDDM Child Patients under 18 Years Old]. Purakutisu [Journal of Practical Diabetes], 16, 302-306. (In Japanese)

[23] Sohmiya, M., Yonehara, S., Sumikawa, M., et al. (2004) Tounyoubyou no nyuuin nissuu ni eikyou wo oyobosu youin ni kansuru kentou [Review of the Factors Influencing the Diabetic Patients' LOS in the Hospital]. Rinsyou to Kenkyuu [The Japanese Journal of Clinical and Experimental Medicine], 81, 1031-1033. (In Japanese)

[24] Nawata, K. and Kawabuchi, K. (2015) Financial Sustainability of the Japanese Medical Payment System: Analysis of the Japanese Medical Expenditure for Educational Hospitalization of Patients with Type 2 Diabetes. Health, 7, 1007-1021. http://dx.doi.org/10.4236/health.2015.78118

[25] Nawata, K. and Kawabuchi, K. (2016) Comparison of the Length of Stay and Medical Expenditures among Japanese Hospitals for Type 2 Diabetes Treatments: The Box-Cox Transformation Model under Heteroscedasticity. Health, 8, 49-63. http://dx.doi.org/10.4236/health.2016.81007

[26] Box, G.E.P. and Cox, D.R. (1964) An Analysis of Transformation. Journal of the Royal Statistical Society B, 26, 211-252.

[27] Sakia, R.M. (1992) The Box-Cox Transformation Technique: A Review. The Statistician, 41, 169-178. http://dx.doi.org/10.2307/2348250

[28] Hossain, M.Z. (2011) The Use of Box-Cox Transformation Technique in Economic and Statistical Analyses. Journal of Emerging Trends in Economics and Management Sciences, 2, 32-39.

[29] Showalter, M.H. (1994) A Monte Carlo Investigation of the Box-Cox Model and a Nonlinear Least Squares Alternative. Review of Economics and Statistics, 76, 560-570. http://dx.doi.org/10.2307/2109980

[30] Nawata, K. (2013) A New Estimator of the Box-Cox Transformation Model Using Moment Conditions. Economics Bulletin, 33, 2287-2297.

[31] Nawata, K. (2015) Robust Estimation Based on the Third-Moment Restriction of the Error Terms for the Box-Cox Transformation Model: An Estimator Consistent under Heteroscedasticity. Economics Bulletin, 3, 1056-1064.

[32] Ministry of Health, Labour and Welfare, DPC Evaluation Division, Central Social Insurance Medical Council (2015) Singi shiryou, DPC hyouka bunnkakai, heisei 26 nen 9 gatsu 5 nichi. Documents for the meeting of the DPC Evalua- 
tion Division on 5 September 2014. (In Japanese)

[33] Basu, A., Manning, W.G. and Mullahy, J. (2004) Comparing Alternative Models: Log vs Cox Proportional Hazard? Health Economics, 13, 749-765.

[34] Cox, D.R. (1972) Regression Models and Life-Tables. Journal of the Royal Statistical Society, Series B, 34, $187-220$. 